\title{
EDITORIAL
}

\section{DATAFIED RESEARCH}

\section{Christian Ulrik Andersen \& Geoff Cox}

APRJA Volume 4, Issue 1, 2015

ISSN 2245-7755

CC license: 'Attribution-NonCommercial-ShareAlike'. 
This issue of $A P R J A$ examines the implications of datafication for research. Following a research workshop at the School of Creative Media, City University of Hong Kong in October 2014, it addresses the thematic framework of the 2015 transmediale festival "Capture All" as a research topic: "to investigate and propose actions that push against the limits of today's pervasive quantification of life, work and play", as the call explains. Indeed, to what extent does data "capture all" - even research?

We produce, share, collect, archive, use and misuse, knowingly or not, massive amounts of data, but what does its "capture" do to us? What are the inter-subjective relations between data-commodity and human subjects? In asking these questions, the articles in this journal seek insights into the logics of data flows between materials, things, data, code, software, interfaces and other stuff that permeates the cultures of datafication. Rather than merely mimicking the sciences' use of (big) data, the arts and humanities must explore what kind of sensorium datafication generates for things and humans. What are the implications of being data? What are the darker forces involved in capturing and using data?

In Evil Media, Andy Goffey and Matthew Fuller write:

A set of words in a report, article, or illicit data dump becomes significant in a different way when placed in a mechanism that allows or even solicits unfettered access, than when that set of words is lodged in a closed directory or laid out as a book; allowing such open access has direct and pragmatic effects on the reception of ideas, to mention just one scale at which they might be operative.
By appealing for an unsolicited and open organisation and access to data, they implicitly highlight how datafication not only is a question of archiving and accessing data content and building information architectures of metadata. The computer is not just a medium that stores and displays but is capable of also reading and writing automatically. This affects human thinking, creativity, notions of life and death, and other relations between data and human experience.

Datafied research is both a thing and a process, and expresses a complex materiality comprised of assemblages of humans and nonhumans. The politics of data distribution are key here, in understanding how various correlations occur and causation (for a correlation does not mean that one thing causes the other). How does this relate to processes of individuation, to the shadowy presence of non-human readers and writers of data? A playful response to datafication points to how readers and writers by no means have become mere automatons.

In common with the transmediale call, the articles in this issue provide responses that "outsmart and outplay" the logic of capturing everything applied by the corporate as well as scientific communities (and, it seems to us that the emerging field of Digital Humanities raises as many questions as it answers in this respect). Each in their own way address this complexity, and examine datafication's connection to commodification, and even to zombification. Articles examine alternatives such as obfuscation in order to know and unknow things at different registers and scales; from the grain of data to big data, the materiality of data and the politics of data structures, or in other ways afforded by emergent practices of datafied research. Such notions lead the authors to address the many aspects of what datafication does to us, and how we might begin to do things to it.

Aarhus, January 2015 